\title{
Analysis of Cytology and Expression of Resistance Genes in Maize Infected with Sporisorium reilianum
}

\author{
Fengkun Qi, Lin Zhang, Xiaojie Dong, Hong Di, Jiayue Zhang, Minhao Yao, Ling Dong, Xing Zeng, and Xianjun Liu, \\ Zhenhua Wang, ${ }^{\dagger}$ and Yu Zhou ${ }^{\dagger}$
}

Northeast Agricultural University, Changjiang Road, Xiangfang District, Harbin, Heilongjiang Province, China 150030

\begin{abstract}
Head smut, caused by the fungus Sporisorium reilianum, is a devastating global disease of maize (Zea mays). In the present study, maize seedlings were artificially inoculated with compatible mating-type strains of S. reilianum by needle inoculation of mesocotyls (NIM) or by soaking inoculation of radicles (SIR). After NIM or SIR, Huangzao4 mesocotyls exhibited severe damage with brownish discoloration and necrosis, whereas Mo17 mesocotyls exhibited few lesions. Fluorescence and electron microscopy showed that $S$. reilianum infected maize within 0.5 day

apoptosis-like features, and hyphae became sequestered within dead cells. In contrast, in Huangzao4, pathogen invasion resulted in autophagy that failed to prevent hyphal spreading. The growth of $S$. reilianum hyphae diminished at 6 days after inoculation when expression of the $R$ genes $Z m W A K$ and $Z m N L$ peaked. Thus, 6 days after SIR inoculation might be an important time for inhibiting the progress of $S$. reilianum infection in maize. The results of this study will provide a basis for further analysis of the mechanisms of maize resistance to $S$. reilianum.
\end{abstract} after SIR and mainly colonized the phloem. With longer incubation, the density of $S$. reilianum hyphae increased in the vascular bundles, concentrated mainly in the phloem. In Mo17, infected cells exhibited
Keywords: maize, head smut, Sporisorium reilianum, expression of disease-resistance genes
Head smut is a fungal disease caused by the soil-borne pathogen Sporisorium reilianum, which occurs in most maize-growing areas worldwide and poses a great threat to maize (Zea mays L.) production (Martinez et al. 2002). In northern China, head smut has caused losses of 10 to $15 \%$, or about 0.3 million tons annually, of total yield (Jin et al. 2000). This disease can be prevented or controlled using measures such as field management and fungicidal seed coating; however, high costs, environmental pollution, and poor stability make these approaches less desirable. Development of head smut-resistant cultivars and analysis of molecular mechanisms of smut resistance are now the favored methods for controlling this disease (Wang et al. 2002).

QTL for resistance to head smut have been detected on nine of the 10 maize chromosomes, excepting chromosome 7, and a major resistance QTL was identified in bin 2.09 (Chen et al. 2008; Ji et al. 2007; Li et al. 2008; Lu and Brewbaker 1999; Lübberstedt et al. 1999; Shi et al. 2009; Weng et al. 2012). Many types of molecular markers including SSRs, dCAPs, SNP markers, and others have been developed by analyzing head smut-resistant (Mo17, Qi319, Ji1037) and -susceptible (Huangzao4, Ji154, 444) inbred lines (Chen et al. 2008; Di et al. 2015a; Weng et al. 2012). The major resistance gene $Z m W A K$ in bin 2.09 was cloned from the highly head smut-resistant maize inbred line Mo17. ZmWAK is highly expressed in mesocotyls

${ }^{\dagger}$ Corresponding authors: Y. Zhou; zhouyu0924@126.com, and Z. Wang; zhenhuawang_2006@163.com

Fengkun Qi and Lin Zhang contributed equally to this research.

Funding: This work was supported financially by the National Natural Science Foundation of China, grant no. 31571670, and The Young Talents Project of Northeast Agricultural University, grant no. 17QC03.

*The $\boldsymbol{e}$-Xtra logo stands for "electronic extra" and indicates that one supplementary figure and one supplementary table are published online.

The author(s) declare no conflict of interest.

Accepted for publication 30 March 2019.

(C) 2019 The American Phytopathological Society and encodes a cell wall-associated receptor kinase that induces disease-related responses in maize. The responses induced by $\mathrm{ZmWAK}$ expression thereby inhibit the growth of S. reilianum and increase maize resistance to head smut (Zuo et al. 2015). The ZmNL gene, also in bin 2.09, encodes a disease resistance-related NBSLRR protein. Using Agrobacterium-mediated transformation, the $Z m N L$ gene controlled by the promoter of the maize ubiquitin gene has been transformed into the highly head smut-susceptible inbred Huangzao4. The rate of head smut in three $T_{2}$ transgenic lines was reduced by $18.38-29.40 \%$ compared with the wild-type control. This result showed that overexpressing $Z m N L$ in head smut-susceptible maize could enhance resistance to head smut caused by $S$. reilianum (Di et al. 2015a). The 19 SNPs associated with smut resistance in maize which involve 18 disease resistance genes were detected by genome-wide association analysis. The gene GRMZM2G047152 was the one of 18 disease resistance genes that was a typical plant disease resistance $R$ gene that encoded the protein with NBS domain (Wang et al. 2012). BLAST of the sequence at NCBI gives the best hit results as $Z$. mays putative disease resistance RPP13-like protein 1 (LOC103635657), transcript variant X1, mRNA.

At present, the most common methods used to inoculate maize with $S$. reilianum include the field soil inoculation method, the friction method, the injection method, and the smear method. Although field soil inoculation is effective and reliable, its shortcomings include a longer incubation period, inability to determine the exact time of inoculation, the large land area required, the large plant populations required for evaluation, and a relatively large environmental impact. Therefore, artificial inoculation of teliospore suspensions in the laboratory is usually performed using the friction, smear, or injection methods. The smear method is simple to use but suffers from poor reproducibility in terms of infection efficiency. The injection and smear methods ensure effective invasion of tissues by $S$. reilianum but cause additional damage to maize plants. In addition, due to the specific conditions required for germination of $S$. reilianum teliospores, inoculation with teliospores alone does not guarantee teliospore germination and cannot ensure infection. Therefore, some researchers have germinated teliospores in advance to prepare teliospore suspensions for inoculation. Inoculating with suspensions of germinated teliospores both enhances the rate of infection and negates the need to mechanically damage the leaves to induce infection (Martinez et al. 2002; Zhang et al. 2013). However, the proportion of 
the four spore mating types produced after germinating teliospores is random, and it is impossible to guarantee that the ratio of these four mating types would be 1:1:1:1. Thus, there may be significant differences in the incidence of mating types in different inoculation batches, and the repeatability of tests is not guaranteed. Teliospores of $S$. reilianum strains obtained from Schirawski et al. (2005) were isolated and their mating types identified as a1b1 (SRZ1) or a2b2 (SRZ2). Artificial inoculation with these mating-type strains (SRZ1, SRZ2) ensures the reproducibility of tests while ensuring an adequate infection rate. Further, the two inoculation methods used in this experiment not only ensured that seedling inoculation didn't destroy the radicle, but also ensured the success of inoculation and good repeatability.

Maize resistance to head smut is a complex process that comprises two stages, including resistance to infection and prevention of hyphal expansion (Dickman and Fluhr 2013). In the present study, infection processes in the highly head smut-resistant maize inbred line Mo17 and the highly susceptible maize inbred Huangzao4 were analyzed after needle inoculation of mesocotyls (NIM) or soaking inoculation of radicles (SIR) of maize plants with mixed mating-compatible $S$. reilianum sporidia in growth chambers. The infection and distribution of $S$. reilianum hyphae were observed by TEM and fluorescence microscopy. The expression of disease-resistance genes in Mo17 and Huangzao4 before and after inoculation was analyzed by qRT-PCR. Understanding the expression of resistance genes in maize after using different inoculation methods to initiate infection should provide an improved system for future analyses of the mechanism of resistance to $S$. reilianum.

\section{Materials and Methods}

Plant materials and S. reilianum strains. Mo17, a maize inbred line that belongs to the US Lancaster heterotic group, is highly head smut-resistant and exhibits a disease incidence of only 0 to $2 \%$ when infected by $S$. reilianum. Highly head smut-susceptible Huangzao4 is an elite Chinese inbred line that shows about $75 \%$ susceptibility to $S$. reilianum under field conditions (Chen et al. 2008; Weng et al. 2012). Compatible $S$. reilianum mating-type strains SRZ1 and SRZ2 were donated by Prof. Schirawski from Göttingen University in Germany (Schirawski et al. 2005) and stored at $-80^{\circ} \mathrm{C}$ until use.

Artificial inoculation of plants with $S$. reilianum. Compatible mating-type strains SRZ1 and SRZ2 of $S$. reilianum were inoculated into $2 \mathrm{ml}$ of $2.4 \%$ potato dextrose broth (PDB) (Difco, Detroit, MI, U.S.A.). Inoculated cultures were shaken at $200 \mathrm{rpm}$ and incubated for $8-12 \mathrm{~h}$ at $28^{\circ} \mathrm{C}$. These cultures were subsequently used as inoculum for $50 \mathrm{ml}$ PDB cultures that were grown overnight under the same conditions until they reached an optical density at $600 \mathrm{~nm}$ $\left(\mathrm{OD}_{600}\right)$ of $0.5-1.0$. SRZ1 and SRZ2 cells were then harvested by centrifugation of the cultures for $5 \mathrm{~min}$ at 3,500 rpm, and the pelleted cells were resuspended to an $\mathrm{OD}_{600}$ of 2.0 in water. Then the resuspended SRZ1 and SRZ2 cells were mixed together to use to inoculate maize seedlings (Di et al. 2017; Gillissen et al. 1992). Deionized water was substituted for cell suspensions to perform control mock inoculations.

Maize seeds were grown in sterile sand in a growth chamber under 15-h day/9-h night $\left(25^{\circ} \mathrm{C}\right)$ with light intensity of $10,000 \mathrm{~lx}$ and $80 \%$ relative humidity. When the mesocotyls of the seedlings were about $1-2 \mathrm{~cm}$ in length, the seedlings were removed from the growth medium and treated with the mixture of $S$. reilianum SRZ1 and SRZ2 sporidia using either NIM or SIR. NIM was performed using a sterile 1-ml syringe to inject $0.5 \mathrm{ml}$ of mixed mating-compatible sporidia of $S$. reilianum per plant into the lower part of mesocotyls of germinating maize seeds. Uninfected controls were performed by injecting the same amount of $\mathrm{ddH}_{2} \mathrm{O}$ into germinating maize seedling mesocotyls. SIR was performed by soaking maize radicles in mixed matingcompatible sporidia of $S$. reilianum for $30 \mathrm{mins}$, then the inoculated seeds were placed into germination medium for further growth. Deionized water was again used as a control to perform control mock inoculations. Samples were taken at 1-day intervals and stored frozen at $-80^{\circ} \mathrm{C}$. At least five plants were sampled at each time point, and each time point was replicated three times.
WGA staining. Wheat germ agglutinin (WGA) staining was performed as in Ghareeb et al. (2011). At 1 to 8 days after inoculation, mesocotyls were sliced into thin sections and placed into 2-ml tubes. Samples were washed with distilled water once, then soaked overnight in $10 \% \mathrm{KOH}$. Samples were then washed again three times with distilled water and incubated in the WGA staining solution $(10 \mathrm{mg} / \mathrm{ml}$ WGA, $0.02 \%$ [vol/vol] Tween 20 in phosphate-buffered saline (PBS) $\mathrm{pH}$ 7.4) for $30 \mathrm{~min}$ under vacuum infiltration. After washing with PBS three times, samples were observed under an Olympus FV 1000 fluorescence microscope with $488 \mathrm{~nm}$ excitation and 500 to $540 \mathrm{~nm}$ emission (Zhang et al. 2017).

Transmission electron microscopy. At 1 to 8 days after inoculation, pieces of mesocotyl tissue (ca. $\left.1 \times 2 \mathrm{~mm}^{2}\right)$ in size were excised from above the points of inoculation and were immediately fixed in $2.5 \%(\mathrm{vol} / \mathrm{vol})$ glutaraldehyde in $0.01 \mathrm{M}$ phosphate buffer, $\mathrm{pH} 6.8$, for $3 \mathrm{~h}$, including 5-min vacuum-infiltration, washed three times for 10 min each in buffer, and were then postfixed for $3 \mathrm{~h}$ in $1 \%$, $\mathrm{wt} / \mathrm{vol}$ osmium tetroxide in $0.01 \mathrm{M}$ phosphate buffer, $\mathrm{pH}$ 6.8. After washing three times for $10 \mathrm{~min}$ each in buffer, samples were dehydrated in an ethanol series followed by acetone, and were then embedded in epoxy resin in flat embedding molds (Suzuki et al. 2017). At each time point, infection sites were identified under a light microscope prior to ultrathin sectioning. Ultrathin sections were collected on an LKB Ultratome V ultramicrotome (LKB-V, LKB, Sweden) and were stained with uranyl acetate and lead citrate. Sections were observed on a Hitachi 7650 TEM (Hitachi High-Tech Science Co, Tokyo, Japan).

Quantitative real-time PCR. Infected and uninfected mesocotyls were sampled over 8 days. Total RNA was extracted from samples for each genotype and treatment at each time point. First-strand cDNA was synthesized according to the instructions of the reverse transcription Kit (TransGen, Beijing, China) using high-quality RNA as a template. Reaction mixtures for qRT-PCR consisted of $2 \mu \mathrm{l}$ of cDNA, $10 \mu \mathrm{l}$ of TransStartR Tip Green qPCR SuperMix, $0.4 \mu \mathrm{l}$ of forward primer $(10 \mu \mathrm{l}), 0.4 \mu \mathrm{l}$ of reverse primer $(10 \mu \mathrm{M})$, and $7.2 \mu \mathrm{l}$ of RNase Free $\mathrm{ddH}_{2} \mathrm{O}$; qRT-PCR was performed on a LightCycler 96 (Roche, Switzerland). The temperature cycling conditions were: $94^{\circ} \mathrm{C}$ for $30 \mathrm{~s}$, then 40 cycles of $94^{\circ} \mathrm{C}$ for $5 \mathrm{~s}$ and $50^{\circ} \mathrm{C}$ for $15 \mathrm{~s}$. The fold-change in expression of genes of interest was normalized to Actin1 expression, and relative expression was determined using the $2^{-\Delta \Delta C t}$ method (Zhang et al. 2017). The mean and standard deviation were calculated from three biological replicates. qPCR was performed three times for each biological replicate. All genes and primer sequences are listed in Supplementary Table S1.

\section{Results}

Resistance gene reduces $S$. reilianum invasion in mesocotyls. In 2014, a marker specific for maize head smut, SR3, was amplified from $S$. reilianum DNA samples using gene-specific primers $(\mathrm{Xu}$ 1999) to confirm the identity of the strains maintained at Harbin by DNA sequencing. The amplified sequences were used as blast queries, and alignments indicated that the sequences amplified from the strains at Harbin were $100 \%$ identical to those maintained by Professor Schirawski at Göttingen.

Mesocotyls of maize were collected from Mo17 and Huangzao4 at 2, 6, and 8 days after NIM with S. reilianum (Fig. 1). At 2 days after NIM, mesocotyls of the uninfected group exhibited normal growth (Fig. 1A and G), whereas both Mo17 and Huangzao4 exhibited small, defined lesions at inoculation sites (Fig. 1D and J). At 6 days after NIM, Huangzao4 mesocotyls began to show brownish discoloration (Fig. 1E), whereas Mo17 mesocotyls had only a few minor lesions (Fig. 1K). At 8 days after NIM, Huangzao4 mesocotyls exhibited severe damage with brownish discoloration and necrosis, whereas Mo17 mesocotyls still had only a few minor lesions (Fig. $1 \mathrm{~F}$ and $\mathrm{L}$ ).

At 2 days after SIR, mesocotyls of Huangzao4 appeared symptomless (Fig. 1P), whereas a handful of Mo17 mesocotyls showed a few small lesions resembling hypersensitive response (HR)-like cell death (Fig. 1V). By 6 days after SIR, Huangzao4 mesocotyls had shrunken and some of the cells had died, whereas Mo17 mesocotyls 
NIM

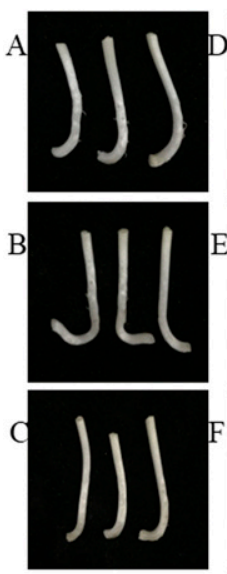

non-infected

Huangzao4
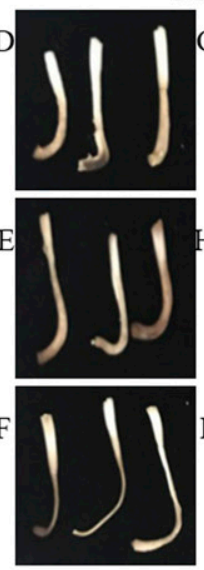

infected

Huangzao
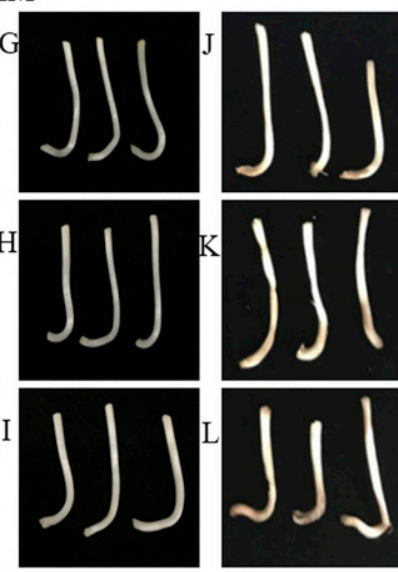

non-infected

$\mathrm{Mo} 17$
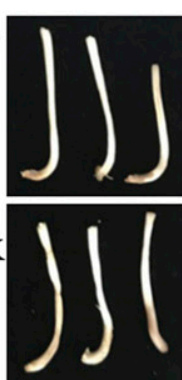

infected

Mo17
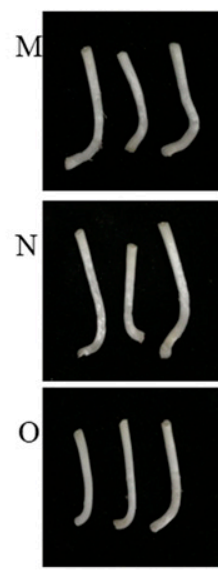

non-infected

Huangzao4

SIR
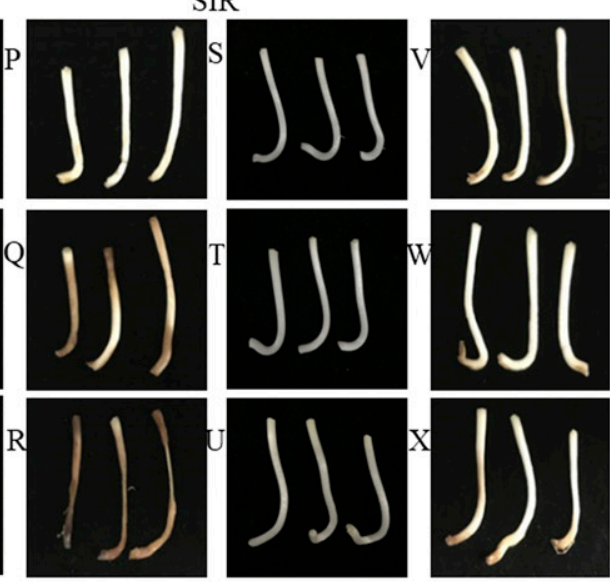

8 day

Fig. 1. Symptom development of maize mesocotyls in response to colonization by Sporisorium reilianum. (A-C) Uninfected Huangzao4 at 2, 6, or 8 days after inoculation with water using NIM; (D-F) infected Huangzao4 at 2, 6, or 8 days after inoculation with S. reilianum using NIM; (G-I) uninfected Mo17 at 2, 6, or 8 days after inoculation with water using NIM; (J-L) infected Mo17 at 2, 6, or 8 days after inoculation with S. reilianum using NIM; (M-O) uninfected Huangzao4 at 2, 6, or 8 days after inoculation with water using SIR; (P-R) infected Huangzao4 at 2, 6, or 8 days after inoculation with S. reilianum using SIR; (S-U) uninfected Mo17 at 2, 6, or 8 days after inoculation with water using SIR; (V-X) infected Mo17 at 2, 6, or 8 days after inoculation with S. reilianum using SIR.

NIM

SIR
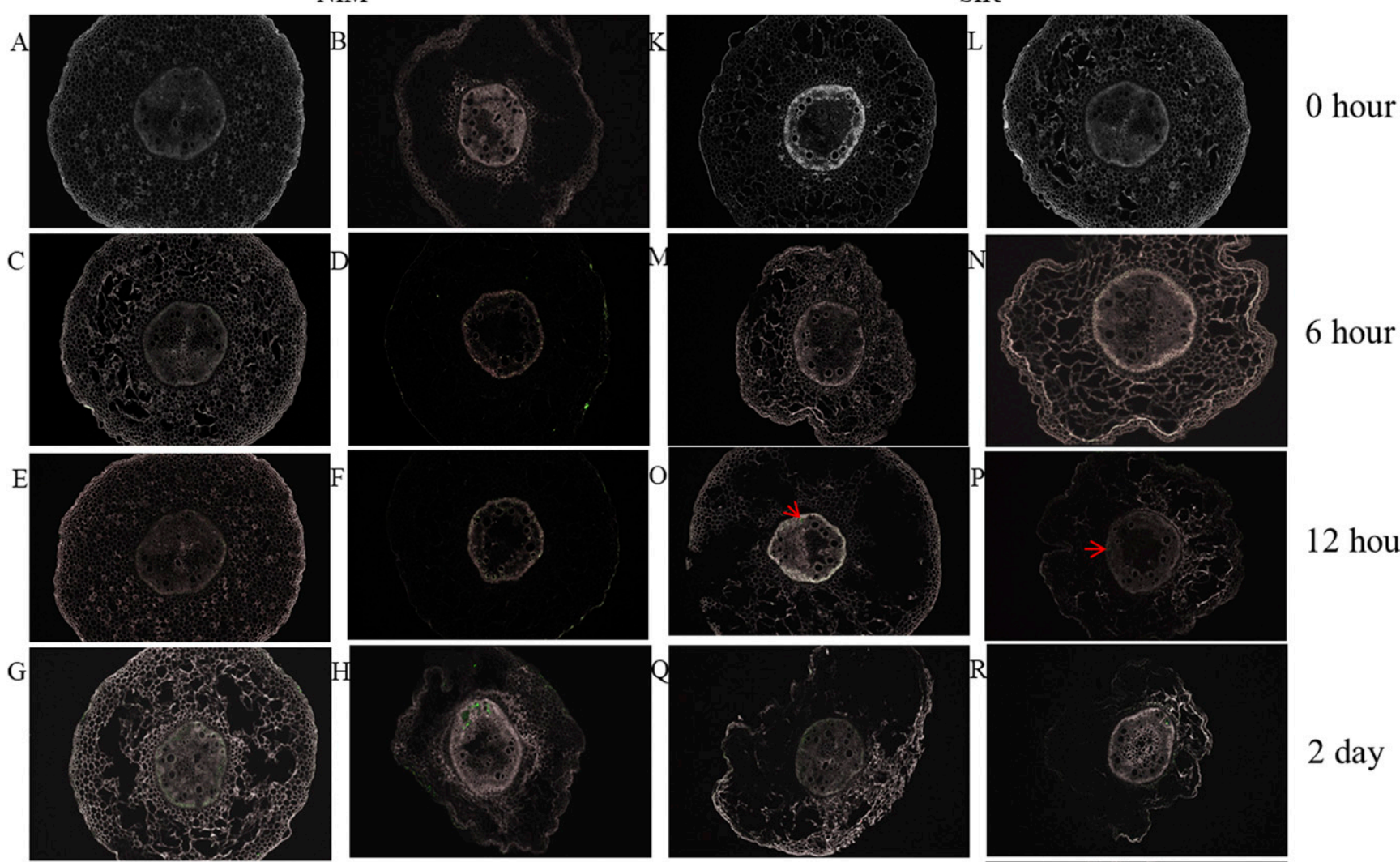

6 hour
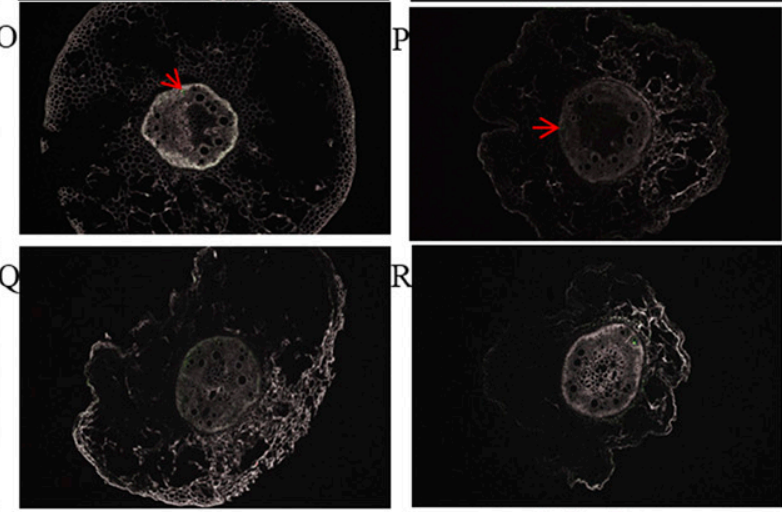

12 hour

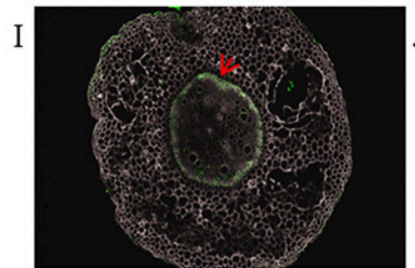

Huangzao4

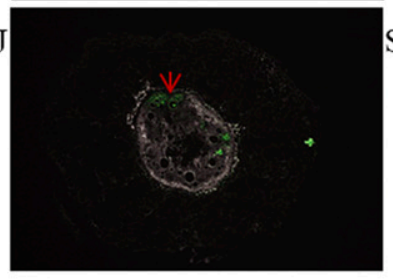

Mo17

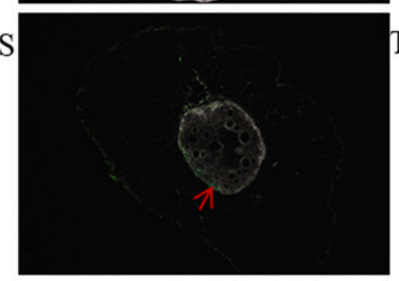

Huangzao4

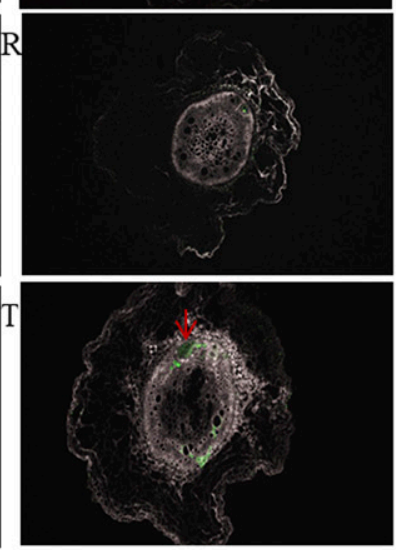

Mo17

Fig. 2. Fluorescence microscopic images of Sporisorium reilianum invasion of tissues of Huangzao4 and Mo17. Inoculated Huangzao4 samples at A, 0 h; C, 6 h; E, 12 h; G, 2 days; or I, 6 days after NIM. Inoculated Mo17 samples at B, 0 h; D, 6 h; F, 12 h; H, 2 days; or J, 6 days after NIM. Inoculated Huangzao4 samples at K, 0 h; M, 6 h; 0, 12 h; Q, 2 days; or S, 6 days after SIR. Inoculated Mo17 samples at L, 0 h; N, 6 h; P, 12 h; R, 2 days; or T, 6 days after SIR. Scale bars, $1 \mathrm{~mm}$. The green area indicated by the red arrow shows S. reilianum hyphae. 
appeared essentially the same as when observed at 2 days after SIR (Fig. 1Q and W). At 8 days after SIR, Huangzao4 mesocotyls exhibited severe damage with brownish discoloration and necrosis, whereas Mo17 mesocotyls still had few lesions (Fig. 1R and X).

A key step to ensure infection with $S$. reilianum is for the pathogen to colonize shoot apical meristems (SAMs) (Ghareeb et al. 2011); thus, the presence or absence of $S$. reilianum hyphae in SAMs was investigated by PCR using the $S$. reilianum-specific primer SR3 at 8 days after inoculation. The percentage of infection in SAMs was strikingly different between the two inbred lines. When using SIR, $92 \pm 2 \%$ of Huangzao4 SAMs were infected, significantly greater than the $6 \pm 1 \%$ of Mo17 SAMs infected. When using NIM, $95 \pm$ $3 \%$ of Huangzao 4 SAMs were infected, significantly greater than the $6 \pm 1 \%$ of Mo17 SAMs infected (Supplementary Fig. S1). The differences in cytological features of mesocotyls and SAM invasion percentages observed between genotypes and treatments showed that $S$. reilianum hyphal growth differed between these two inbred lines.
Symptoms of head smut were also identified in tassels or ears of Huangzao4 plants infected using either NIM or SIR.

Growth of $S$. reilianum hyphae in infected maize. Staining of $S$. reilianum in transverse mesocotyl sections with WGA-Alexa Fluor 488 revealed that in inoculated mesocotyls, $S$. reilianum hyphae had grown mainly in the phloem.

At $0 \mathrm{~h}$ after NIM, S. reilianum hyphae were not observed in either Mo17 or Huangzao4 tissues (Fig. 2A and B). However, after SIR, hyphae were observed at $6 \mathrm{~h}$ after inoculation in tissues of both inbred lines (Fig. 2C and D). At 2 days after inoculation, the relative amount of hyphal growth in both inbred lines was greater when using NIM than when using SIR (Fig. 2G and H). Hyphae were found not only in the maize vascular bundles, but also in the parenchyma cells (Fig. 2I and J). Otherwise, the distribution of hyphae in plants treated with SIR was similar to that in plants treated with NIM.

At $0 \mathrm{~h}$ after SIR, S. reilianum hyphae were not observed in either Mo17 or Huangzao4 tissues under the fluorescence microscope (Fig. $2 \mathrm{~K}$ and L). At $12 \mathrm{~h}$ after inoculation, S. reilianum hyphae were

NIM
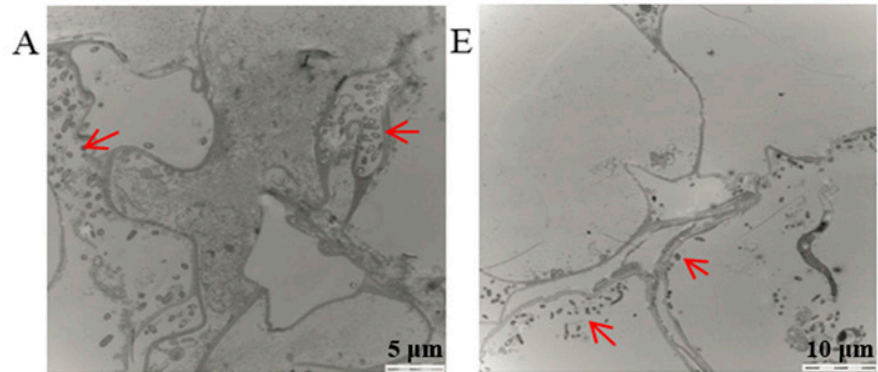

$\mathrm{B}$
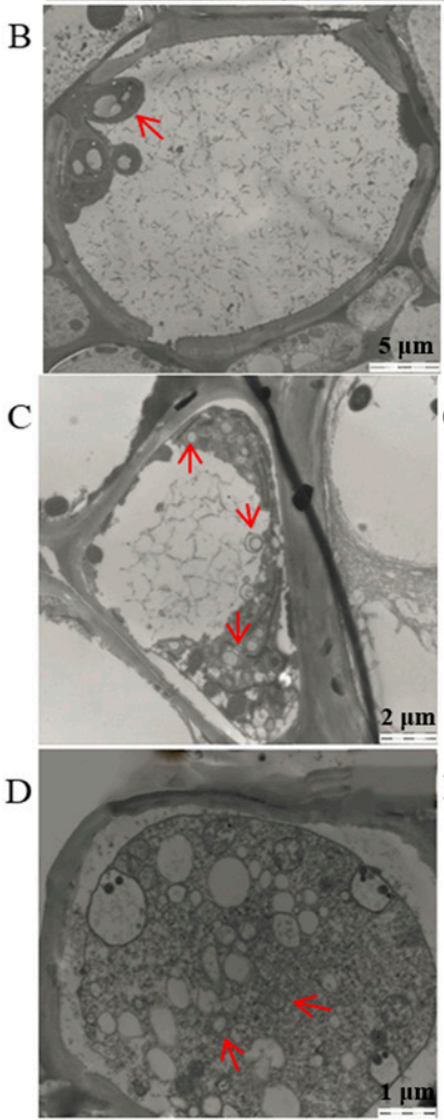

Huangzao4
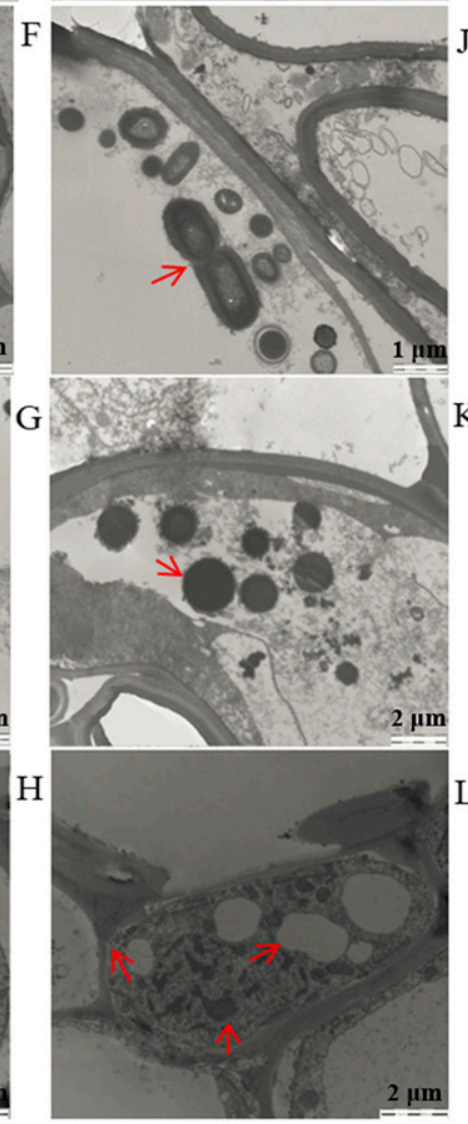

Mo17

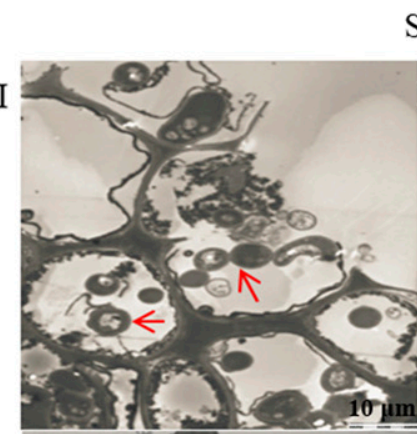

SIR
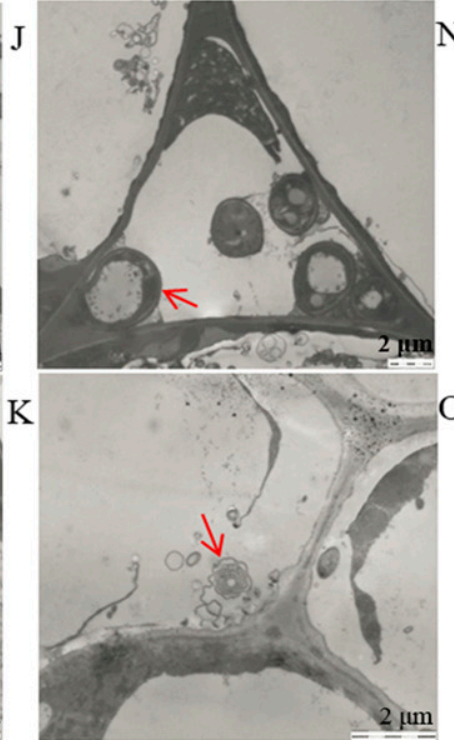

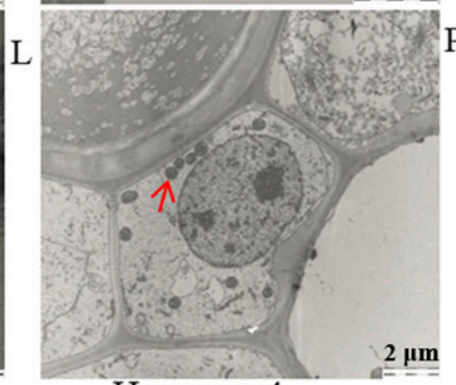

Huangzao4
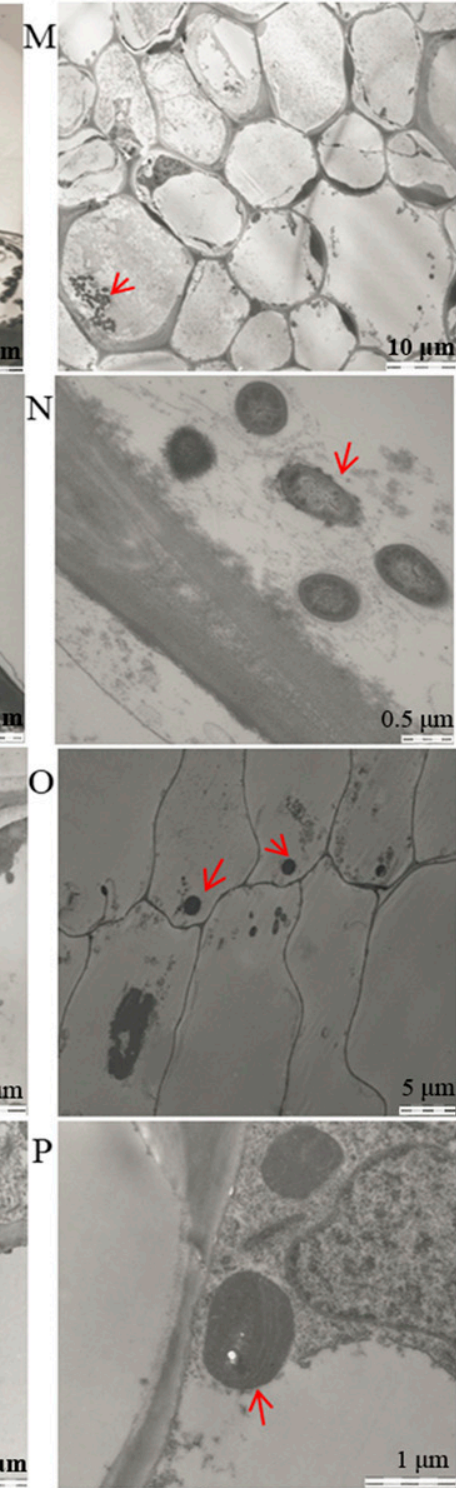

Mo17

Fig. 3. Transmission electron microscopic (TEM) images of cells of Sporisorium reilianum-infected Huangzao4 and Mo17 tissues. A-D, Infected Huangzao4 samples after NIM; E-H, Infected Mo17 samples after NIM; I-L, Infected Huangzao4 samples after SIR; M-P, Infected Mo17 samples after SIR. Panels B and J show large autophagic vacuoles present within cells of maize tissues infected with $S$. reilianum hyphae. Red arrows in panels $\mathbf{C}, \mathbf{D}$, and $\mathbf{K}$ indicate autolysosome/autophagosome-like structures. Panels $\mathbf{F}$ and $\mathbf{N}$ show autophagic vacuoles absent from cells of maize tissues infected with $\mathbf{S}$. reilianum hyphae. Panels $\mathbf{G}$ and $\mathbf{O}$ show increased abundance of peroxisomes in the cytoplasm. Panel $\mathbf{P}$ shows mitochondrial swelling in cells of maize tissues infected with $\mathbf{S}$. reilianum hyphae. Panel $\mathbf{H}$ shows the plasma membrane contracted away from the cell wall, plasma membrane blebbing, and vacuolar rupture in cells of maize tissues infected with $S$. reilianum hyphae. 
observed in the vascular bundles of Huangzao4 (Fig. $2 \mathrm{O}$ and P). Subsequently, $S$. reilianum hyphae gradually increased in the vascular bundles, mainly in the phloem. These observations allow us to infer that $S$. reilianum grows upward through the phloem in the vascular bundles of maize mesocotyls, reaches the SAM, and eventually causes characteristic black powdery head smut symptoms in maize tassels and ears. We found no differences in numbers of S. reilianum hyphae between the two inbred lines at the initial stages of infection, but by only 2 days after inoculation, there were noticeable differences in numbers and distribution of $S$. reilianum hyphae between Huangzao4 and Mo17. Although S. reilianum hyphae grew steadily in Huangzao4, hyphal growth was impeded early after invasion of a few cells in Mo17 (Fig. 2Q-R). S. reilianum hyphae are more dispersed in Huangzao4 and more densely distributed in Mo17, as shown in Figures $2 \mathrm{~S}$ and $\mathrm{T}$.

Ultrastructural changes in host cells interacting with S. reilianum. The ultrastructure of Mo17 and Huangzao4 cells inoculated with $S$. reilianum were observed to identify cellular and subcellular characteristics associated with infection by pathogens.

At 1 day after NIM, S. reilianum hyphae could be observed in tissues of both Mo17 and Huangzao4. In Huangzao4 infected using NIM, large vacuoles were present within cells of maize tissues containing $S$. reilianum hyphae (Fig. 3B). In addition, S. reilianum hyphae were more dispersed in Huangzao4 than in Mo17 (Fig. 3A). Cells in Huangzao4 maize tissues infected with $S$. reilianum exhibited double-membrane structures typical of autophagy (Fig. $3 \mathrm{C}$ and D). These characteristics were visible by both fluorescence microscopy and TEM. In Mo17 infected using NIM, the distribution of $S$. reilianum hyphae was denser than that in Huangzao4 (Fig. 3E). Vacuoles were absent from cells of Mo17 tissues containing $S$. reilianum hyphae, and the abundance of peroxisomes in the cytoplasm of these cells increased (Fig. 3F and G). Moreover, infected Mo17 exhibited features diagnostic of apoptotic-like programmed cell death (AL-PCD) such as chromatin fragmentation, cell shrinkage, and plasma membrane blebbing (Fig. 3H).

Hyphae of S. reilianum were not observed in either Mo17 or Huangzao4 at 1-3 days after inoculation. However, hyphae of $S$. reilianum were observed in both Mo17 and Huangzao4 at 4 days after inoculation. A series of changes had taken place in maize cells upon $S$. reilianum invasion and in vivo expansion of hyphae. Although autophagy occurred in Huangzao4 cells upon invasion of $S$. reilianum hyphae, this process failed to prevent hyphal spreading. (Fig. 3I and K). Large vacuoles were present within cells containing $S$. reilianum hyphae in infected Huangzao4 at 7 days after inoculation. However, the mitochondria in cells of infected maize tissues appeared normal rather than swollen (Fig. 3J and L). In contrast, S. reilianum hyphal growth was severely inhibited in resistant Mo17 relative to susceptible Huangzao4. Infected cells in Mo17 exhibited AL-PCD with fungal hyphae confined inside dead plant cells (Fig. 3M). Large vacuoles consistent with autophagy were not present within Mo17 cells infected with $S$. reilianum hyphae (Fig. 3N). Instead, cells of infected Mo17 exhibited increased peroxisome abundance, plasmolysis, vacuole rupture, and swollen mitochondria (Fig. $3 \mathrm{O}$ and P). Highly electron-dense deposits appeared between the maize cell walls and plasma membranes, especially in contact with the hyphae, that might have been due to secretions from the hyphae (Fig. 3N).
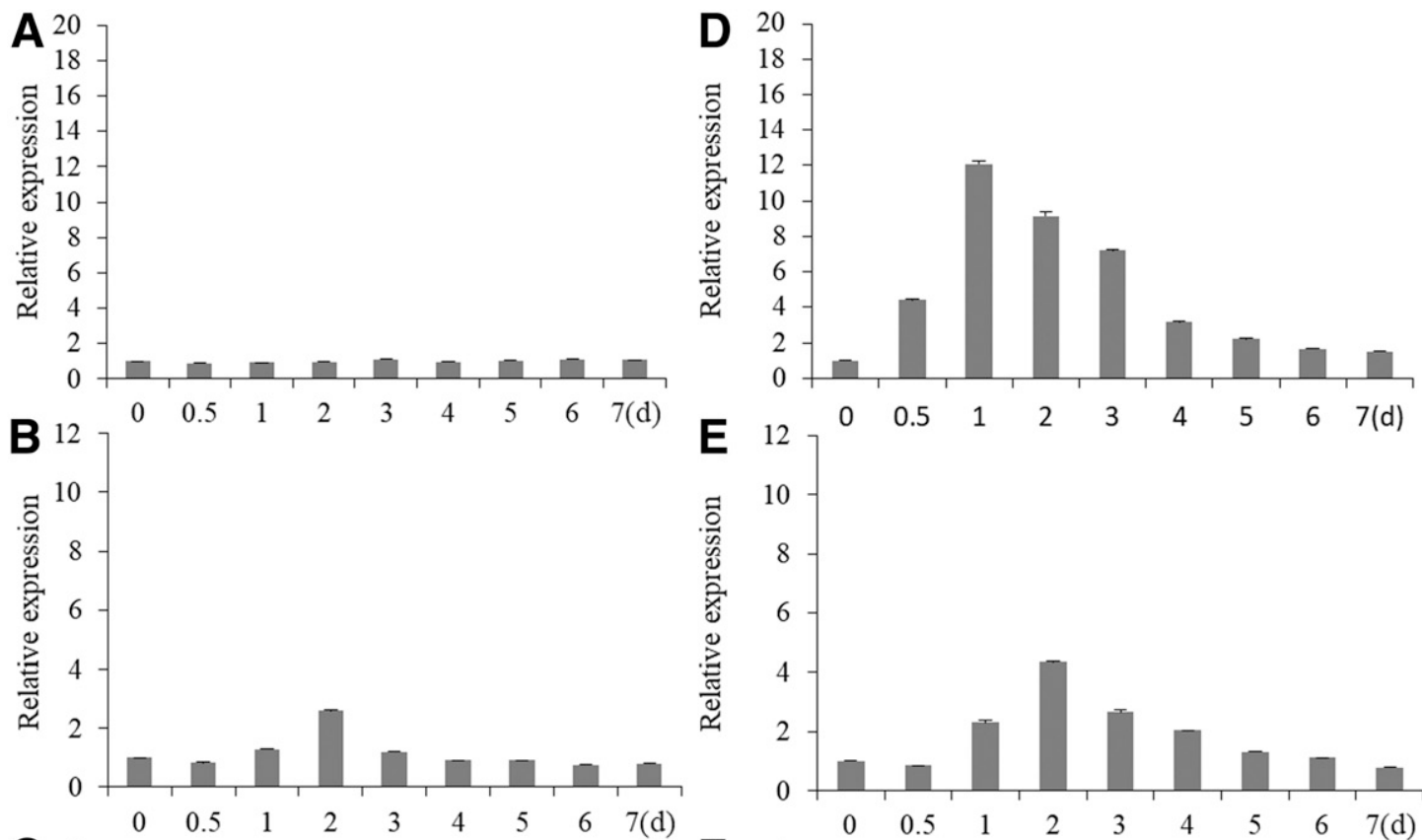

$Z m W A K$
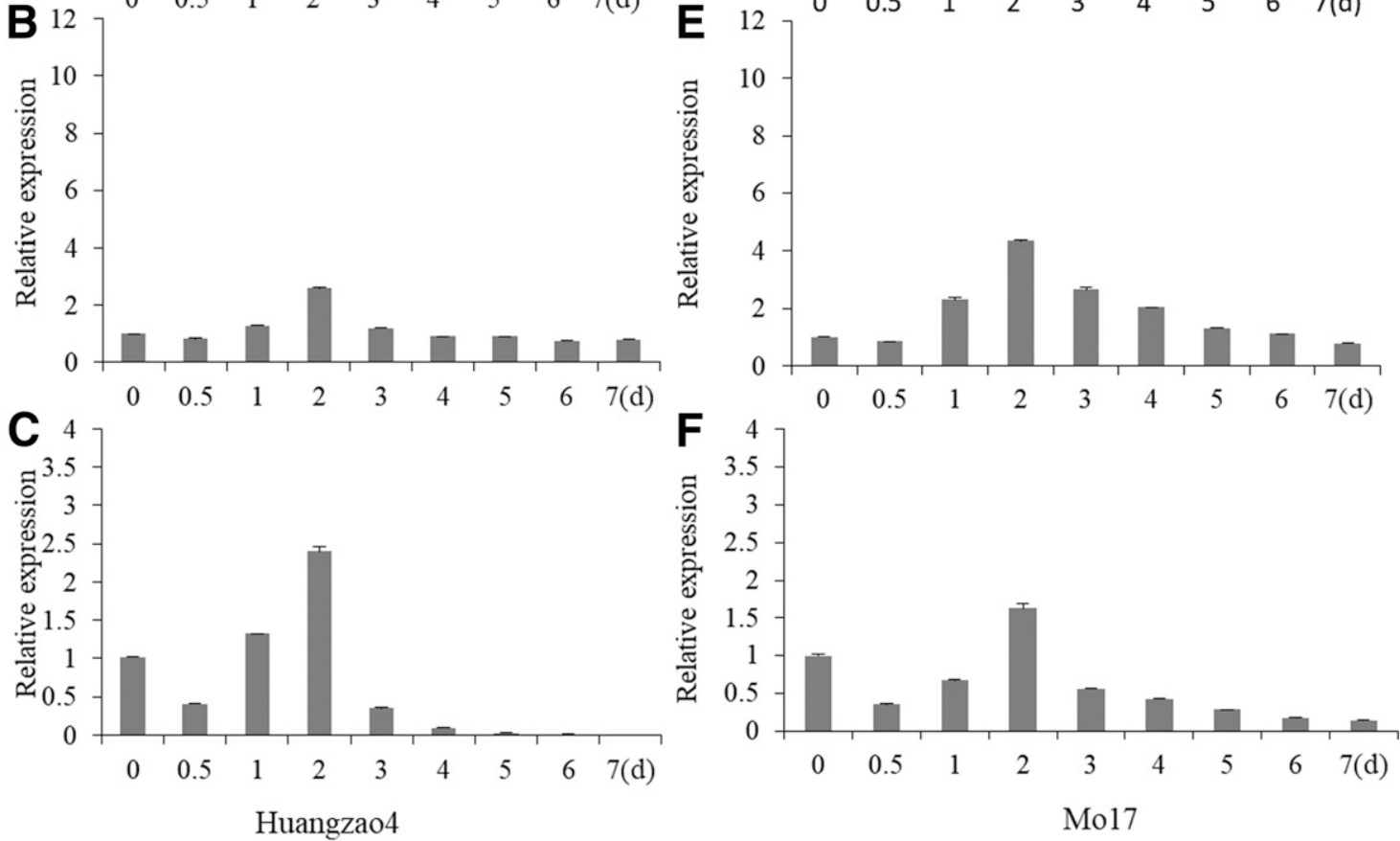

$Z m N L$

GRMZM2G047152

Fig. 4. Expression of disease-resistance genes in Mo17 and Huangzao4 after NIM with Sporisorium reilianum. Panels A-C show the expression of ZmWAK, ZmNL, and GRMZM2G047152 genes after NIM of S. reilianum in Huangza04; panels D-F show the expression of ZmWAK, ZmNL, and GRMZM2G047152 genes after NIM of S. reilianum in Mo17. 
Expression of disease-resistance genes. Mo17 and Huangzao4 were inoculated with a mixture of sporidia from mating-compatible S. reilianum strains using NIM or SIR. Total RNA was then extracted from Mo17 and Huangzao4 mesocotyls collected from 0 to 8 days after inoculation. Total RNA obtained from uninfected mesocotyls at the same time points was used as a control. The relative expression of the genes were calculated (treatment/control).

In Mo17 and Huangzao4 infected using NIM, the expression of $Z m N L$ and GRMZM2G047152 reached their maxima at 2 days after inoculation relative to the Actin1 control. In Mo17 infected using NIM, relative expression values of ZmNL and GRMZM2G047152 were 4.34 and 1.63, respectively (Fig. 4E and F), and in Huangzao4 infected using NIM were 2.59 and 2.40, respectively (Fig. 4B and C). The expression of $Z m W A K$ reached its maximum on the first day after inoculation in Mo17 with a relative expression value of 12.65 (Fig. 4D). Expression of the $Z m W A K$ gene could not be detected in Huangzao4 (Fig. 4A).

When Mo17 was inoculated with a mixture of sporidia from mating-compatible strains of $S$. reilianum by SIR, the first peaks of $Z m W A K, Z m N L$, and GRMZM2G047152 expression appeared at 2, 3 , and 3 days, respectively, and with relative expression values of 5.74, 4.42, and 2.45, respectively. The expression of $Z m W A K$ and $Z m N L$ peaked at 6 days after inoculation, with significantly increased relative expression values of 17.69 and 10.56. A second peak in GRMZM2G047152 expression appeared at 7 days after inoculation, with a relative expression value of 1.68 (Fig. 5D-F). In Huangzao4, the expression of both $Z m N L$ and GRMZM2G047152 tended to first increase and then decrease, with maxima at 3 and 7 days after inoculation, respectively, and relative expression values of 3.43 and 3.27, respectively (Fig. 5B and C).

\section{Discussion}

The highly head smut-resistant Mo17 maize inbred line and the highly head smut-susceptible line Huangzao4 were chosen to study the differences in infection and expansion of S. reilianum hyphae in maize. Many methods have been used to inoculate maize with the causative agent of head smut, $S$. reilianum, such as soil inoculation, vacuum infiltration, needle inoculation, smear inoculation, friction inoculation, and the soaking method for radicles. The present study analyzed differences in maize cell ultrastructure and gene expression after infection of maize with S. reilianum. NIM and SIR were used as standardized inoculation methods to improve the reproducibility of this research. The advantages of these two artificial inoculation methods include 1) better control of the maize seedling cultivation environment; 2) more quantitative inoculation; 3) minimized contamination of the experiment with other pathogens; 4) more rapid and accurate assessment of disease incidence; and 5) a high infection rate. Further, these methods can also reduce differences in gene expression caused by different culture conditions and provide more reliable methods for systematic analysis of inheritance of resistance, identification of pathogens, analysis of gene expression, and verification of gene function. Both of these methods were accurate, reliable, and easy to implement. SIR seemed better suited to studies of resistance to infection and resistance to hyphal expansion, while
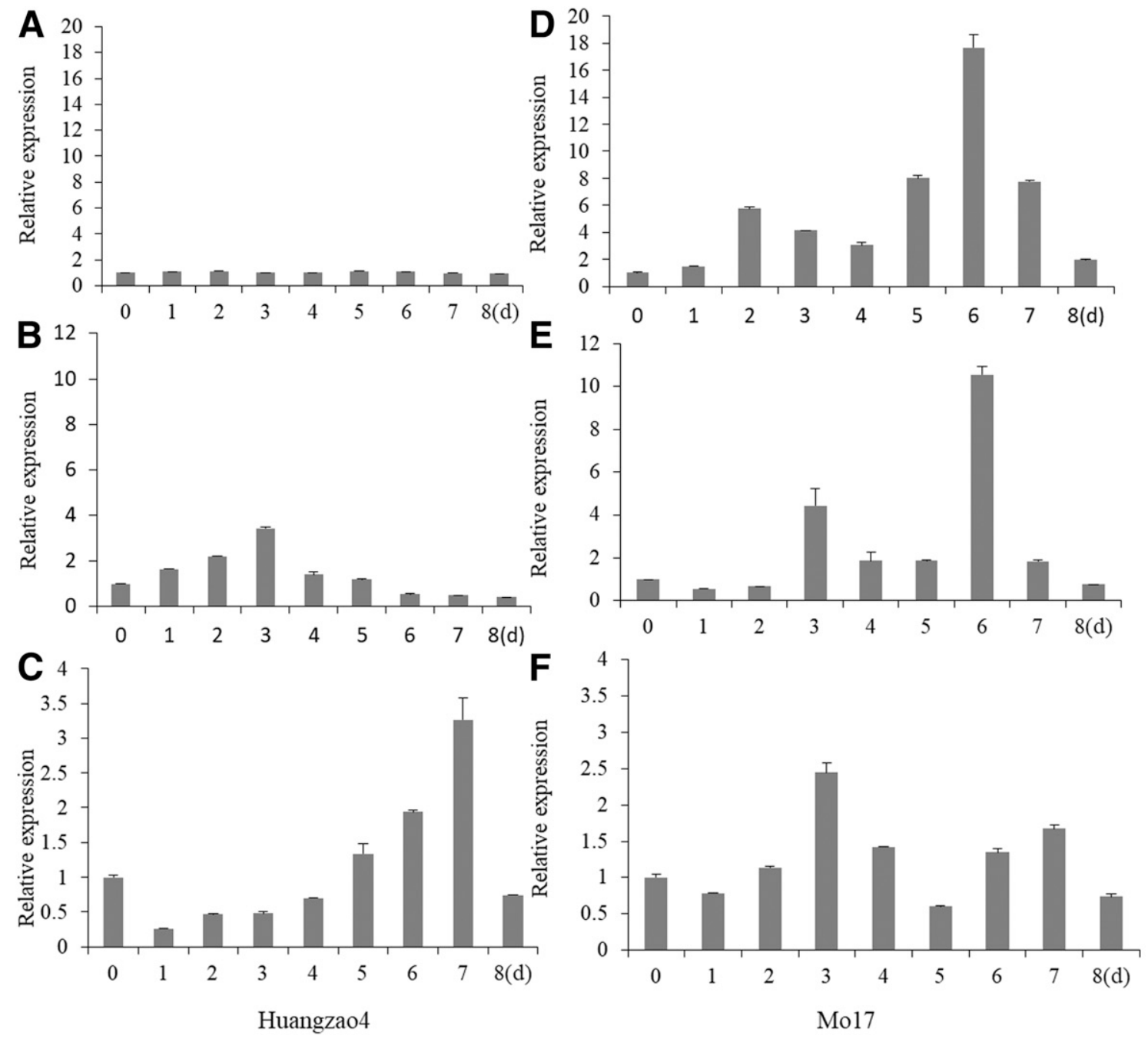

GRMZM2G047152

Fig. 5. Expression of disease-resistance genes in Mo17 and Huangzao4 after SIR with Sporisorium reilianum. Panels A-C show the expression of ZmWAK, ZmNL, and GRMZM2G047152 genes after SIR of S. reilianum in Huangza04; panels D-F show the expression of ZmWAK, ZmNL, and GRMZM2G047152 genes after SIR of S. reilianum in Mo17. 
NIM seemed better suited to studies of resistance to hyphal expansion. The results of this study also describe a suitable system for the study of the cytology, physiology, and genomics of plant-pathogen interactions in maize and the head smut pathogen $S$. reilianum.

In the current study, cytological analysis provided convincing evidence that the mode of cell death controlled the outcome of the interaction between a biotrophic fungus and host (Bianchi et al. 1997; Dangl and Jones 2001; Fu et al. 2015; Kabbage et al. 2013; Leal-Bertioli et al. 2010; Lim et al. 1983; Liu and Bassham 2012; Mims et al. 2000; Toyoda et al. 2016; Wharton et al. 2001). Before the transition to floral meristems in maize SAMs, S. reilianum grows by obtaining nutrients from maize cells. So while AL-PCD in Mo17 impedes continued growth of $S$. reilianum, autophagy in Huangzao4 favors survival of maize cells, but allows fungal growth to continue (Li et al. 2016; Mims et al. 2002; Reape and McCabe 2008; Zhang et al. 2017). Staining S. reilianum-infected maize tissues with the specific dye WGA-Alexa Flour 488 for observation by TEM revealed no apparent differences during the initial infection stage between head smut-resistant line Mo17 and susceptible line Huangzao4. Then at 0.5 day after SIR, $S$. reilianum hyphae were observed in the vascular bundles of both lines, indicating that infection by S. reilianum takes about 0.5 day (Hood and Shew 1996; Reape and McCabe 2008). At 6 days after inoculation, there were noticeable differences in the infection process between these maize lines. Whereas $S$. reilianum hyphae expanded steadily in Huangzao4, they were impeded at an early stage after invasion of a few cells in Mo17. The S. reilianum hyphae were more dispersed in Huangzao4 but more densely distributed in tissues of Mo17 (Fig. 2S and T). These differences in the growth of $S$. reilianum in these lines might be related to the high expression of the $Z m W A K$ gene in Mo17, and its corresponding low expression in Huangzao4, as suggested by previous research (Zuo et al. 2015). In other interactions between plants and fungal pathogens, such as Colletotrichum graminicola in maize roots or Fusarium oxysporum in the roots of tomatoes (Lagopodi et al. 2002; Sukno et al. 2008), early latent infections can occur in which hyphae grow between cells. This coexistence between the hyphae and the host can prevent the host from initiating a strong defense response to cellular damage that would interrupt hyphal growth.

The expression of ZmWAK, ZmNL, and GRMZM2G047152, which are related to head smut resistance in maize, increased similarly in Mo17 during infection with S. reilianum. The expression of these three genes could be related to the hypersensitive response (HR) observed around sites of S. reilianum infection in Mo17 that impede continued pathogen invasion, possibly through PCD (Huot et al. 2014). Expression of the $Z m W A K$ gene reached its maximum at 1 day after inoculation using NIM and was significantly higher at 6 days after inoculation using SIR. This result was identical with that of previous research (Zuo et al. 2015), in which ZmWAK expression began to increase at 0.5 day after inoculation with $S$. reilianum and peaked at 1 to 2 days after inoculation. In the present experiment, $Z m W A K$ expression of might be slightly biased due to differences in inbred lines and inoculation sites between the studies, but both studies showed similar increases in $Z m W A K$ expression. Most disease resistance $(R)$ genes in plants, such as Gro-1.4 (Jürgen et al. 2010) and $R 3 a$ (Huang et al. 2005) in potato, $X a 26$ (Sun et al. 2004) in rice, and $D m 3$ (Shen et al. 2002) in lettuce, are not usually expressed or display low constitutive expression. However, the expression of some of these genes, such as barley Mlal and Mla6, tobacco $N$, or rice $X 7$ (Bieri et al. 2004; Levy et al. 2004; Wei et al. 2011) can be positively regulated by signals from pathogens or the environment. Similarly, the expression of the maize smut-resistance candidate gene $Z m N L$ in this study is also induced by the presence of a pathogen ( $\mathrm{Yu}$ et al. 2014). The expression of $Z m N L$ increased significantly at 1 day after inoculation of Mo17 with S. reilianum using NIM and reached its peak at 2 days after inoculation. Previous research (Di et al. 2017) indicated that the expression of $Z m N L$ also increased in L282 and Huangzao4 after inoculation with S. reilianum, reaching a peak at 2 days after inoculation, and that relative expression of $Z m N L$ in L282 (4.29) was significantly higher than in Huangzao4 (2.99). Thus, as other researchers have observed for other plant $R$ genes, $Z m N L$ expression was low and constitutive in uninfected Mo17 and Huangzao4 plants (Ellis et al. 2000; Jia et al. 2013; Martin et al. 2003; Yu et al. 2014). Importantly, in the present study, the expression of $Z m N L$ increased in Mo17 more than in Huangzao4 upon inoculation with $S$. reilianum. $Z m N L$ expression increased at earlier stages of infection with $S$. reilianum but decreased at later stages of infection. Higher expression of $Z m N L$ in the head smut-resistant line Mo17 than in the susceptible Huangzao4 suggests that $Z m N L$ expression might function in resistance to infection by $S$. reilianum in Mo17.

In the present study, $R$ gene expression and ultrastructural changes were examined in head smut-resistant Mo17 and susceptible Huangzao4 infected with $S$. reilianum after using NIM or SIR to inoculate young plants. $S$. reilianum hyphae grew mainly in the phloem of both lines. With increasing time after inoculation, $S$. reilianum hyphae gradually grew in the vascular bundles and were mainly concentrated in the phloem. Thus, we could infer that $S$. reilianum grew upward through the phloem of maize mesocotyls to reach the SAM and eventually cause characteristic black powdery symptoms of head smut in maize tassels and ears. Fluorescence microscopic and TEM images showed that infection by $S$. reilianum had occurred at 0.5 day, and that the $R$ genes related to head smut resistance were the most highly expressed at about 6 days after expansion, which might be an important time point for inhibiting the progress of $S$. reilianum infection in maize.

\section{Acknowledgments} SRZ2.

We thank Prof. Schirawski for providing the $S$. reilianum strains SRZ1 and

\section{Literature Cited}

Bianchi, A., Zambonelli, A., Zechini D’Aulerio, A., and Bellesia, F. 1997. Ultrastructural studies of the effects of Allium sativum on phytopathogenic fungi in vitro. Plant Dis. 81:1241-1246.

Bieri, S., Mauch, S., and Shen, Q. H. 2004. RARI positively controls steady state levels of barley MLA resistance proteins and enables sufficient MLA6 accumulation for effective resistance. Plant Cell 16:3480-3495.

Chen, Y. S., Chao, Q., Tan, G. Q., Zhao, J., Zhang, M. J., Ji, Q., and Xu, M. L. 2008. Identification and fine-mapping of a major QTL conferring resistance against head smut in maize. Theor. Appl. Genet. 117:1241-1252.

Dangl, J. L., and Jones, J. D. 2001. Plant pathogens and integrated defence responses to infection. Nature 411:826-833.

Di, H., Liu, X. J., Wang, Q. K., Weng, J. F., Zhang, L., Li, X. H., and Wang, Z. H 2015a. Development of SNP-based dCAPS markers linked to major head smut resistance quantitative trait locus qHS2.09 in maize. Euphytica 202:69-79.

Di, H., Yu, T., Deng, Y. X., Dong, X. J., Li, R., Zhou, Y., and Wang, Z. H. 2017. Complementary DNA (cDNA) cloning and functional verification of resistance to head smut disease (Sphacelotheca reiliana) of an NBS-LRR gene ZmNL in maize (Zea mays). Euphytica 213:288.

Dickman, M. B., and Fluhr, R. 2013. Centrality of host cell death in plant microbe interactions. Annu. Rev. Phytopathol. 51:543-570.

Ellis, J., Dodds, P., and Pryor, T. 2000. Structure, function and evolution of plant disease resistance genes. Curr. Opin. Plant Biol. 3:278-284.

Fu, S. M., Hartung, J., Zhou, C. Y., Su, H. N., Tan, J., and Li, Z. A. 2015 Ultrastructural changes and putative phage particles observed in sweet orange leaves infected with 'Candidatus Liberibacter asiaticus'. Plant Dis. 99:320-324.

Ghareeb, H., Becker, A., Iven, T., Feussner, I., and Schirawski, J. 2011. Sporisorium reilianum infection changes inflorescence and branching architectures of maize. Plant Physiol. 156:2037-2052.

Gillissen, B., Bergemann, J., and Sandmann, C. 1992. A two-component regulatory system for self/non-self-recognition in Ustilago maydis. Cell 68:647-657.

Hood, M. E., and Shew, H. D. 1996. Applications of $\mathrm{KOH}$ aniline blue fluorescence in the study of plant-fungal interactions. Phytopathology 86: 704-708.

Huang, S., Vossen, V. D. E. A. G., Kuang, H., Vleeshouwers, V. G. A. A., Zhang, N., and Borm, T. J. A. 2005. Comparative genomics enabled the isolation of the $R 3$ a, late blight resistance gene in potato. Plant J. 42:251-261.

Huot, B., Yao, J., Montgomery, B. L., and He, S. Y. 2014. Growth-defense tradeoffs in plants: A balancing act to optimize fitness. Mol. Plant 7:1267-1287.

Ji, H. L., Li, X. H., Xie, C. X., Hao, Z. F., Lü, X. L., and Shi, L. Y. 2007 Comparative QTL mapping of resistance to Sporisorium reiliana in maize based on meta-analysis of QTL locations. J. Plant Genet. Resour. 8:132-139.

Jia, R. Z., Ming, R., and Zhu, Y. J. 2013. Genome-wide analysis of nucleotidebinding site (NBS) disease resistance $(R)$ genes in sacred lotus (Nelumbo nucifera Gaertn.) reveals their transition role during early evolution of land plants. Trop. Plant Biol. 6:98-116.

Jin, Q. M., Li, J. P., Zhang, X. W., Wang, G., Song, S., Liu, Y., and Wang, L. 2000. Establishment IPM of system of corn diseases and pest insects in the spring corn belt. Maize Sci. 8:84-88. 
Jürgen, P., Heike, H., Jost, M., Khalid, M., Menéndez, C. M., and Francesco, S. 2010. Molecular cloning of the potato Gro1-4 gene conferring resistance to pathotype ro1 of the root cyst nematode Globodera rostochiensis, based on a candidate gene approach. Plant J. 38:285-297.

Kabbage, M., Williams, B., and Dickman, M. B. 2013. Cell death control: The interplay of apoptosis and autophagy in the pathogenicity of Sclerotinia sclerotiorum. PLoS Pathog 9:e1003287.

Lagopodi, A. L., Ram, A. F., Laraers, G. E., Punt, P. J., Ca, V. D. H., Lugtenberg, B. J., and Bloemberg, G. V. 2002. Novel aspects of tomato root colonization and infection by Fusarium oxysporum f. sp. radicis-lycopersici revealed by confocal laser scanning microscopic analysis using the green fluorescent protein as a marker. Mol. Plant-Microbe Interact. 15:172-179.

Leal-Bertioli, S. C. D. M., Farias, M. P. D., Silva, P. T., Guimarães, P. M., Brasileiro, A. C. M., and Bertioli, D. J. 2010. Ultrastructure of the initial interaction of Puccinia arachidis, and Cercosporidium personatum, with leaves of Arachis hypogaea, and Arachis stenosperma. J. Phytopathol. 158: 792-796.

Levy, M., Edelbaum, O., and Sela, I. 2004. Tobacco mosaic virus regulates the expression of its own resistance gene $N$. Plant Physiol. 135:2392-2397.

Li, X. H., Wang, Z. H., Gao, S. R., Shi, H. L., Zhang, S. H., George, M. L. C., Li, M. S., and Xie, C. X. 2008. Analysis of QTL for resistance to head smut (Sporisorium reiliana) in maize. Field Crops Res. 106:148-155.

Li, Y., Kabbage, M., Liu, W., and Dickman, M. B. 2016. Aspartyl protease mediated cleavage of AtBAG6 is necessary for autophagy and fungal resistance in plants. Plant Cell 28:233-247.

Lim, L. L., Fineran, B. A., and Cole, A. L. J. 1983. Ultrastructure of intrahyphal hyphae of Glomus fasciculatum (Thaxter) Gerdemann and Trappe in roots of white clover (Trifolium repens L.). New Phytol. 95:231-239.

Liu, Y., and Bassham, D. C. 2012. Autophagy: Pathways for self-eating in plant cells. Plant Biol. 63:215-237.

Lu, X. W., and Brewbaker, J. L. 1999. Molecular mapping of QTLs conferring resistance to Sphacelotheca reiliana (Kühn). Clint. Maize Genet. Coop. News Lett. 73:36.

Lübberstedt, T., Xia, X. C., Tan, G., Liu, X., and Melchinger, A. E. 1999. QTL mapping of resistance to Sporisorium reilianum in maize. Theor. Appl. Genet. 99:593-598.

Martin, G. B., Bogdanove, A. J., and Sessa, G. 2003. Understanding the functions of plant disease resistance proteins. Annu. Rev. Plant Biol. 54:23-61.

Martinez, C., Roux, C., Jauneau, A., and Dargent, R. 2002. The biological cycle of Sporisorium reilianum f. sp. zeae: An overview using microscopy. Mycologia 94:505-514.

Mims, C. W., Copes, W. E., and Richardson, E. A. 2000. Ultrastructure of the penetration and infection of pansy roots by Thielaviopsis basicola. Phytopathology 90:843-850.

Mims, C. W., Rodriguez-Lother, C., and Richardson, E. A. 2002. Ultrastructure of the host-pathogen interface in daylily leaves infected by the rust fungus Puccinia hemerocallidis. Protoplasma 219:221-226.

Reape, T. J., and McCabe, P. F. 2008. Apoptotic like programmed cell death in plants. New Phytol. 180:13-26.

Schirawski, J., Heinze, B., Wagenknecht, M., and Kahmann, R. 2005. Mating type loci of Sporisorium reilianum: Novel pattern with three a and multiple b specificities. Eukaryot. Cell 4:1317-1327.
Shen, K. A., Chin, D. B., Arroyo-Garcia, R., Ochoa, O. E., Lavelle, D. O., and Wroblewski, T. 2002. Dm3 is one member of a large constitutively expressed family of nucleotide binding site-leucine-rich repeat encoding genes. Mol Plant-Microbe Interact. 15:251-261.

Shi, H. L., Li, X. H., Zhang, D. G., Xie, C. X., Hao, Z. F., and Li, M. S. 2009. Development of sequence characterized amplified region (SCAR) primers for the detection of resistance to Sporisorium reiliana in maize. Agric. Sci. China 8:910-919.

Sukno, S. A., Garcia, V. M., Shaw, B. D., and Thon, M. R. 2008. Root infection and systemic colonization of maize by Colletotrichum graminicola. Appl. Environ. Microbiol. 74:823-832.

Sun, X., Cao, Y., Yang, Z., Xu, C., Li, X., and Wang, S. 2004. Xa26, a gene conferring resistance to Xanthomonas oryzae pv. oryzae in rice, encodes an LRR receptor kinase-like protein. Plant J. 37:517-527.

Suzuki, T., Maeda, A., Hirose, M., Ichinose, Y., Shiraishi, T., and Toyoda, K 2017. Ultrastructural and cytological studies on Mycosphaerella pinodes infection of the model legume Medicago truncatula. Front. Plant Sci. 8:1132.

Toyoda, K., Yao, S., Mai, T., Uchioki, M., Miki, M., and Tanaka, K. 2016. The plant cell wall as a site for molecular contacts in fungal pathogenesis. Physiol. Mol. Plant Pathol. 95:44-49.

Wang, M., Yan, J., Zhao, J., Song, W., Zhang, X., and Xiao, Y. 2012. Genomewide association study (GWAS) of resistance to head smut in maize. Plant Sci. 196:125-131

Wang, Z., Jiang, Y., Wang, L., Jin, Y., Li, X. H., and Shi, H. 2002. Research advance on head smut disease in maize. Maize Sci. 10:61-64.

Wei, J. L., Chen, S., Zeng, L. X., Yang, J. Y., Liu, X. Q., and Zhu, X. Y. 2011 Quantitative expression analysis of rice bacterial blight resistant candidate genes of Xa7 by real-time fluorescent quantitative PCR. Mol. Plant Breed. 9: 9-16.

Weng, J. F., Liu, X. J., Wang, Z. H., Wang, J., Zhang, L., and Hao, Z. 2012. Molecular mapping of the major resistance quantitative trait locus qHS2.09 with simple sequence repeat and single nucleotide polymorphism markers in maize. Phytopathology 102:692-699.

Wharton, P. S., Julian, A. M., and O'Connell, R. J. 2001. Ultrastructure of the infection of Sorghum bicolor by Colletotrichum sublineolum. Phytopathology 91:149-158.

Xu, M. L. 1999. Species-specific detection of maize pathogens Sporisorium reiliana and Ustilago maydis by dot blot hybridization and PCR-based assays. Plant Dis. 83:390-395.

Yu, T., Wang, Z. H., Jin, X. C., Liu, X. J., and Kan, S. S. 2014. Analysis of gene expression profiles in response to Sporisorium reilianum $\mathrm{f}$. $\mathrm{sp}$. zeae in maize (Zea mays L.). Electron. J. Biotechnol. 17:230-237.

Zhang, N., Zhang, B. Q., Zuo, W. L., Xing, Y. X., Konlasuk, S., Tan, G. Q., Zhang, Q. Q., Ye, J. R., and Xu, M. L. 2017. Cytological and molecular characterization of $Z m W A K$-mediated head-smut resistance in maize. Mol. Plant-Microbe Interact. 30:455-465.

Zhang, S., Gardiner, J., Xiao, Y., Zhao, J., Wang, F., and Zheng, Y. 2013. Flora transition in maize infected with Sporisorium reilianum disrupts compatibility with this biotrophic fungal pathogen. Planta 237:1251-1266.

Zuo, W. L., Chao, Q., Zhang, N., Ye, J. R., Tan, G. Q., Li, B. L., and Xu, M. L. 2015. A maize wall-associated kinase confers quantitative resistance to head smut. Nat. Genet. 47:151-157. 